\title{
Source model of the 2005 west off Fukuoka prefecture earthquake estimated from the empirical Green's function simulation of broadband strong motions
}

\author{
Wataru Suzuki and Tomotaka Iwata \\ Disaster Prevention Research Institute, Kyoto University, Gokasho, Uji, Kyoto 611-0011, Japan
}

(Received August 9, 2005; Revised November 17, 2005; Accepted November 21, 2005; Online published January 27, 2006)

\begin{abstract}
We estimated strong motion generation area (SMGA) source model which is responsible for broadband $(0.2$, $0.3-10 \mathrm{~Hz}$ ) strong motions of the 2005 west off Fukuoka prefecture earthquake and its largest aftershock using the empirical Green's function (EGF) method. The estimated SMGAs are almost corresponding to the large slip area deduced by kinematic waveform inversion. The SMGA rupture for the mainshock propagated mainly upward and toward the northwest with rupture velocity of $3.15 \mathrm{~km} / \mathrm{s}$. The size of the SMGA follows the self-similar empirical formula of the asperity size derived by Somerville et al. (1999). The stress drop of the mainshock SMGA is calculated to be $10.7 \mathrm{MPa}$, which is larger than those of the largest aftershock SMGA and the aftershocks used as EGF.
\end{abstract}

Key words: Empirical Green's function method, broadband strong motion, source model, stress drop.

\section{Introduction}

At 10:53 on 20 March 2005, an $M_{J} 7.0$ (magnitude determined by Japan Meteorological Agency, JMA) earthquake occurred in the off-shore of the Fukuoka prefecture, northern Kyushu island, Japan. This event, the 2005 west off Fukuoka prefecture earthquake, was a crustal earthquake with left lateral strike slip (Fig. 1). There was little seismicity before this earthquake and this is the first time to record the JMA seismic intensity 6 - since the observation had started for this area. Several kinematic waveform inversion analyses have revealed the slip distributions in detail using strong motion records (e.g. Asano and Iwata, 2006; Horikawa, 2006; Kobayashi et al., 2006; Sekiguchi et al., 2006). In these analyses, the frequency band is limited to lower than $1 \mathrm{~Hz}$ because precise information of underground structure is necessary to construct numerical Green's function to synthesize the higher-frequency ground motions. On the other hand, the empirical Green's function (EGF) method, which uses records of a small earthquake as Green's function, is able to provide realistic ground motions including high-frequency component. In order to investigate the source characteristics that are responsible for strong motions up to higher frequency, we estimated the strong motion generation area (SMGA, Miyake et al., 2003) from broadband $(0.2-10 \mathrm{~Hz})$ strong motion simulation using the EGF method proposed by Irikura (1986).

SMGA is a rectangular area with no explicit heterogeneities of slip, stress drop and rupture velocity inside it (Miyake et al., 2003). This simple source model has successfully been applied to explain broadband ground motions of many large to moderate-sized earthquakes. The

Copyright (c) The Society of Geomagnetism and Earth, Planetary and Space Sciences (SGEPSS); The Seismological Society of Japan; The Volcanological Society of Japan; The Geodetic Society of Japan; The Japanese Society for Planetary Sciences; TERRAPUB.
SMGAs roughly correspond to the large slip areas on the fault deduced by kinematic inversion in studies of the recent destructive earthquakes (e.g. the 1994 Northridge earthquake, by Kamae and Irikura, 1998a; the 1995 Hyogoken Nanbu earthquake, by Kamae and Irikura, 1998b; the 2000 Tottori-ken Seibu earthquake, by Ikeda et al., 2002). More quantitatively, Miyake et al. (2003) showed that the SMGA corresponds to the asperity area which is characterized from slip distribution according to the criterion by Somerville et al. (1999) for three moderate-sized crustal earthquakes. Since important characteristics of broadband ground motions can be explained by large slip or large slipvelocity regions on ruptured fault as shown in studies presented above, the concept of the characterized source model used for strong motion prediction has been developed. We, therefore, analyze the SMGA, not only for illustrating the source physics, but also for advancing and testing the source model for strong motion prediction.

A month after the mainshock, the largest aftershock $\left(M_{J}\right.$ 5.8) occurred at the southern edge of the total rupture area of the mainshock inferred from kinematic inversion and aftershock distribution. We also estimated the SMGA and compared its source characteristics with respect to the mainshock.

\section{Estimation of SMGA for the Mainshock \\ 2.1 Data and analysis procedure}

For the waveforms of the 2005 west off Fukuoka prefecture earthquake, the $P$-wave amplitudes of the first arrival phases $(P 1)$ are small and larger phases $(P 2)$ arrived a few seconds later. Horikawa (2006) estimated that the main rupture started $3.6 \mathrm{~km}$ to the southeast and $4 \mathrm{~km}$ deeper than the hypocenter $3.3 \mathrm{~s}$ after the origin time from the $P 2-P 1$ arrival time differences. Sekiguchi et al. (2006) did a similar analysis and found the starting point of the main rupture was located $4 \mathrm{~km}$ along the strike and $1 \mathrm{~km}$ along the down- 
Table 1. Source parameters of the mainshock and the EGF event. Superscripts $* 1, * 2, * 3, * 4$ denote the parameters determined by Kyushu University, JMA, F-net, and Hi-net, respectively. Seismic moment of the EGF event is estimated from the $S$-wave amplitude spectra observed at KiK-net stations.

\begin{tabular}{lrr}
\hline & Mainshock & EGF event \\
\hline Origin time & $2005 / 03 / 2010: 53$ & $2005 / 04 / 1020: 34$ \\
Hypocentral location (Latitude, Longitude, Depth) & $\left(33.75^{\circ} \mathrm{N}, 130.16^{\circ} \mathrm{E}, 14.0 \mathrm{~km}\right)^{* 1}$ & $\left(33.67^{\circ} \mathrm{N}, 130.28^{\circ} \mathrm{E}, 4.7 \mathrm{~km}\right)^{* 2}$ \\
JMA magnitude $\left(M_{J}\right)$ & 7.0 & 5.0 \\
Focal mechanism $($ Strike, Dip, Rake) & $\left(122^{\circ}, 87^{\circ},-11^{\circ}\right)^{* 3}$ & $\left(290^{\circ}, 82^{\circ}, 32^{\circ}\right)^{* 4}$ \\
Seismic moment $\left(M_{W}\right)$ & $7.80 \times 10^{18} \mathrm{Nm}(6.6)^{* 3}$ & $2.00 \times 10^{16} \mathrm{Nm}(4.8)$ \\
\hline
\end{tabular}

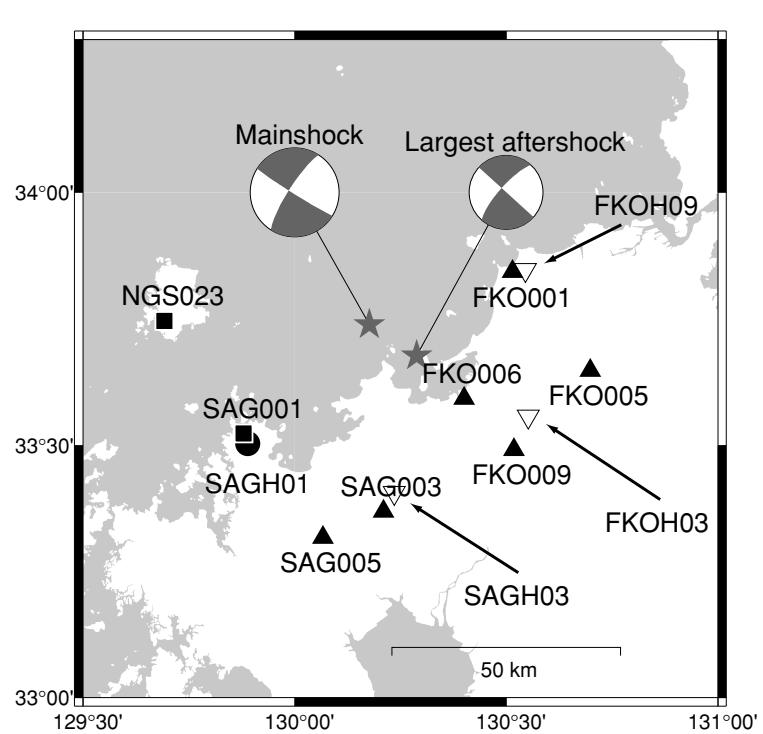

Fig. 1. Epicenters and focal mechanisms (determined by F-net moment tensor inversion) of the mainshock and the largest aftershock of the 2005 west off Fukuoka prefecture earthquake and strong motion observation stations used in this analysis. For the mainshock, we used stations indicated by triangles and squares. For the largest aftershock, we used stations indicated by triangles and circle. Inverted triangles show KiK-net stations used to estimate the seismic moment of the EGF event for the mainshock.
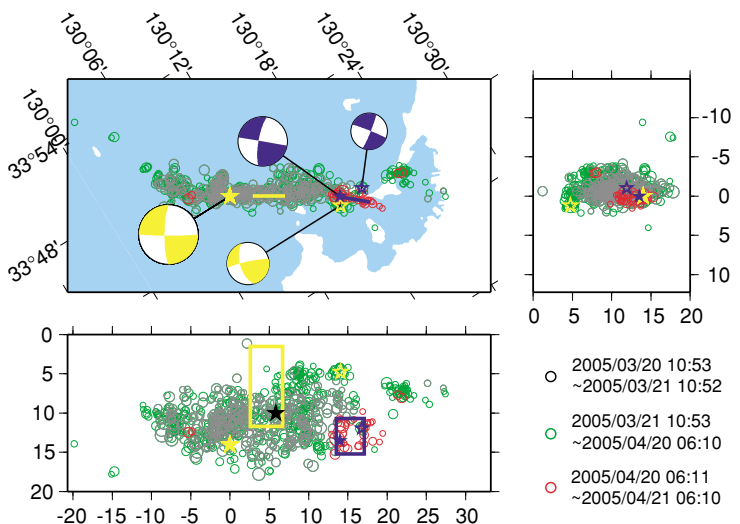

- 2005/03/20 10:53

2005/03/21 10:53

$\sim 2005 / 04 / 20$ 06:10

2005/04/20 06:11

$\sim 2005 / 04 / 2106: 10$

Fig. 2. Location of the estimated SMGAs and aftershock distributions on the horizontal map and two cross-section profiles; one is along the strike of the mainshock $\left(122^{\circ}\right)$ and the other is perpendicular to it. Yellow solid star is the hypocenter of the mainshock and yellow open star is that of the EGF event. Yellow rectangle shows the mainshock SMGA with black star indicating the rupture starting subfault of the SMGA. Blue stars and rectangle correspond to those of the largest aftershock.
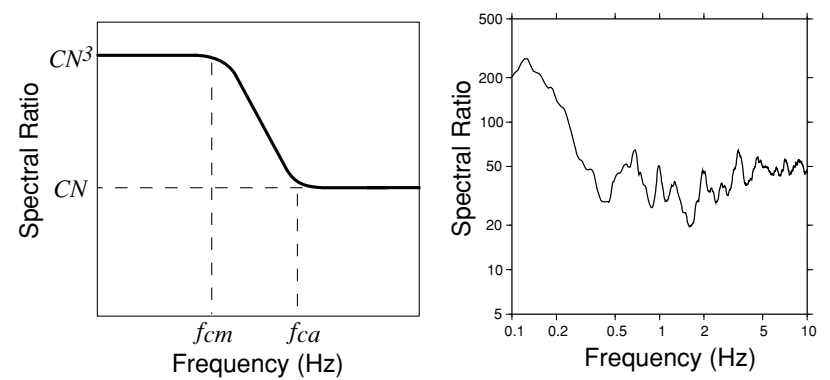

Fig. 3. Schematic illustration of spectral ratio between the target and EGF events (left) and averaged $S$-wave spectral ratio observed at FKO001, FKO005, NGS023 and SAG001 (right). Observed spectra are smoothed by moving average using window between $\pm 10 \%$ of the center frequency.

dip and the rupture delay time was $3.3 \mathrm{~s}$ with respect to the initial rupture. Most kinematic waveform inversion results showed that the amount of final slip around the hypocenter was small and large slip area is observed in the southern shallow part of the fault. Taking the results above into consideration, we construct a source model comprised of one SMGA, whose influence will dominate among the observed strong motion records.

As the EGF, we used records of a $M_{J} 5.0$ aftershock whose source parameters are listed together with those of the mainshock in Table 1. We referred to F-net moment tensor solution catalog for the focal mechanism and the seismic moment of the mainshock. For the EGF event, whose moment tensor solution did not appear in the catalog, we adopted focal mechanism which Hi-net automatically determined from polarities of $P$-wave first motions and the seismic moment estimated from flat level of $S$-wave displacement spectra observed at three KiK-net borehole stations shown in Fig. 1. The EGF event had a similar focal mechanism to the mainshock and is located to the southeast of the mainshock hypocenter (Fig. 2). The selected EGF would be suitable to explain the dominant phases of strong motion records, which are thought to be mainly radiated from the southern part of the fault. Under the assumption of the $\omega^{-2}$ source spectral scaling, the EGF method by Irikura (1986) needs two ratios between the target event and the EGF event which is calculated from spectral ratios of two events. One is the ratio of length scale of the two events, $N$, with which the SMGA (originally the fault) is divided into subfaults as $N \times N$. The other is the ratio of the stress drop of the two events, $C$, which is assumed constant over each subfault 
Table 2. Estimated (best) parameters of the SMGA of the mainshock (upper) and variation of each parameter for 10 trials when rupture velocity is 3.15 $\mathrm{km} / \mathrm{s}$ (lower). Rupture starting point and delay time are those relative to the mainshock initial rupture. The location of the SMGA is found in Fig. 2.

\begin{tabular}{cccccc}
\hline Length & Width & Rise time & Rupture starting point & Delay time & Rupture velocity \\
\hline $4.1 \mathrm{~km}$ & $10.2 \mathrm{~km}$ & $1.96 \mathrm{~s}$ & $6 \mathrm{~km} \mathrm{SE}, 4 \mathrm{~km} \mathrm{up}$-dip & $3.3 \mathrm{~s}$ & $3.15 \mathrm{~km} / \mathrm{s}$ \\
$4.0-4.4 \mathrm{~km}$ & $10.0-10.9 \mathrm{~km}$ & $1.81-2.02 \mathrm{~s}$ & $6 \mathrm{~km} \mathrm{SE}, 0-6 \mathrm{~km} \mathrm{up}$-dip & $3.0-3.3 \mathrm{~s}$ & \\
\hline
\end{tabular}

Table 3. Source parameters of the largest aftershock and its EGF event. Superscripts *1, *2 denote the parameters determined by JMA and F-net.

\begin{tabular}{lcr}
\hline & Largest aftershock & EGF event \\
\hline Origin time & $2005 / 04 / 2006: 11$ & $2005 / 04 / 0121: 52$ \\
Hypocentral location (Latitude, Longitude, Depth) & $\left(33.68^{\circ} \mathrm{N}, 130.29^{\circ} \mathrm{E}, 13.5 \mathrm{~km}\right)^{* 1}$ & $\left(33.67^{\circ} \mathrm{N}, 130.32^{\circ} \mathrm{E}, 11.9 \mathrm{~km}\right)^{* 1}$ \\
JMA magnitude $\left(M_{J}\right)$ & 5.8 & 4.3 \\
Focal mechanism (Strike, Dip, Rake) & $\left(312^{\circ}, 90^{\circ}, 14^{\circ}\right)^{* 2}$ & $\left(324^{\circ}, 86^{\circ},-5^{\circ}\right)^{* 2}$ \\
Seismic moment (Moment magnitude) & $1.31 \times 10^{17} \mathrm{Nm}(5.4)^{* 2}$ & $1.61 \times 10^{15} \mathrm{Nm}_{(4.1)^{* 2}}$ \\
\hline
\end{tabular}

in this analysis. In Fig. 3, we show the schematic illustration of the spectral ratio of two events and the average ratio calculated from records of FKO001, FKO005, SAG001, NGS023. The flat level in the low-frequency range represents the ratio of the seismic moments, $C N^{3}$, while the ratios also have the flat level in the high-frequency range which corresponds to $C N$ if two events follow the $\omega^{-2}$ scaling. We determined $N=3$ and $C=13.3$. Using these values, waveforms of the mainshock is synthesized by summing up the EGF records over SMGA divided into subfaults of the EGF size. Detailed formulation of the EGF simulation is described in Miyake et al. (2003).

We estimated the parameters of the SMGA by simultaneously minimizing the misfit of envelopes of acceleration waveforms bandpass-filtered between $0.2-10 \mathrm{~Hz}$ and velocity waveforms bandpass-filtered between $0.2-1 \mathrm{~Hz}$ in order to fit synthetic waveforms into observed ones over wide frequency range. Misfits were calculated from Eq. (1).

$$
\text { misfit }=\frac{\int\left(u_{\mathrm{obs}}-u_{\mathrm{syn}}\right)^{2} d t}{\sqrt{\int u_{\mathrm{obs}}^{2} d t} \sqrt{\int u_{\mathrm{syn}}^{2} d t}}
$$

Here, $u_{\text {obs }}$ is waveform or envelope of observation and $u_{\text {syn }}$ is those of simulation. Lower limit of frequency band is determined by signal-to-noise ratio of the EGF records. We used $S$-wave portion of two horizontal components, in a 20 s long window starting from 2 s before the $S$-wave arrivals, at eight K-NET stations whose epicentral distance is less than about $50 \mathrm{~km}$ (Fig. 1). The SMGA was assumed to be located on the fault plane estimated by F-net moment tensor solution and the rupture starting point of the mainshock was assumed as the hypocenter determined by Institute of Seismology and Volcanology, Kyushu University. These fault plane and hypocenter are the same as those used in the kinematic source inversion by Asano and Iwata (2006). Model parameters to be estimated for SMGA are the length, the width, the rise time, the rupture starting time relative to the initial rupture time, the rupture starting subfault of the SMGA, and its relative location from the hypocenter. The genetic algorithm (GA) was employed for these parameter search. Search ranges of model parameters are $0.3-15 \mathrm{~km}$ for the length and the width, 0.03-2.1 s for the rise time, $1.0-5.0 \mathrm{~s}$ for the delay time of the SMGA rupture, and the 0-10 km from the hypocenter along the strike and up-dip direction for the SMGA rupture starting point. Since the GA is the heuristic approach, several trials should be performed to confirm the robustness of the solutions. Therefore, we carried out the GA search ten times, changing the set of initial model parameters. We kept the rupture velocity in the SMGA constant during each GA search. We tried four rupture velocity, $3.15,2.8,2.45$, and $2.1 \mathrm{~km} / \mathrm{s}$, which correspond to the $90,80,70$, and $60 \%$ of the $S$-wave velocity of the source region, respectively.

\subsection{Result}

When the rupture velocity is $3.15 \mathrm{~km} / \mathrm{s}$, or $90 \%$ of the $S$-wave velocity, we obtained the models which gave the smaller residual value than the search with any other rupture velocity. Models derived by ten trials are similar and the best one is listed in Table 2 with variation of the model parameters estimated by ten trials. Location of the estimated SMGA is shown in Fig. 2 with aftershock distribution. The SMGA seems to be located at the area where aftershock activity was low. The SMGA rupture started from a point 6 $\mathrm{km}$ along strike and $4 \mathrm{~km}$ up-dip away from the hypocenter with $3.3 \mathrm{~s}$ delay to the initial rupture time, and propagated upward and northwest. Fig. 4 shows the fittings of observed and synthesized waveforms bandpass-filtered between $0.2-10 \mathrm{~Hz}$ with misfits or residual values of acceleration envelopes $(0.2-10 \mathrm{~Hz})$ and velocity waveforms $(0.2-1$ $\mathrm{Hz}$ ) calculated according to Eq. (1). Residual values of the velocity waveforms may not seem small enough to express that they are in good agreement. However, main characteristics of acceleration and velocity waveforms could be reproduced well for wide frequency band.

Stress drop of a rectangular strike-slip crack with the seismic moment $M_{0}$, the length $L$ and the width $W$ is calculated as follows (Knopoff, 1958; Kanamori and Anderson, 1975).

$$
\Delta \sigma=\frac{2}{\pi} \frac{M_{0}}{W^{2} L}
$$




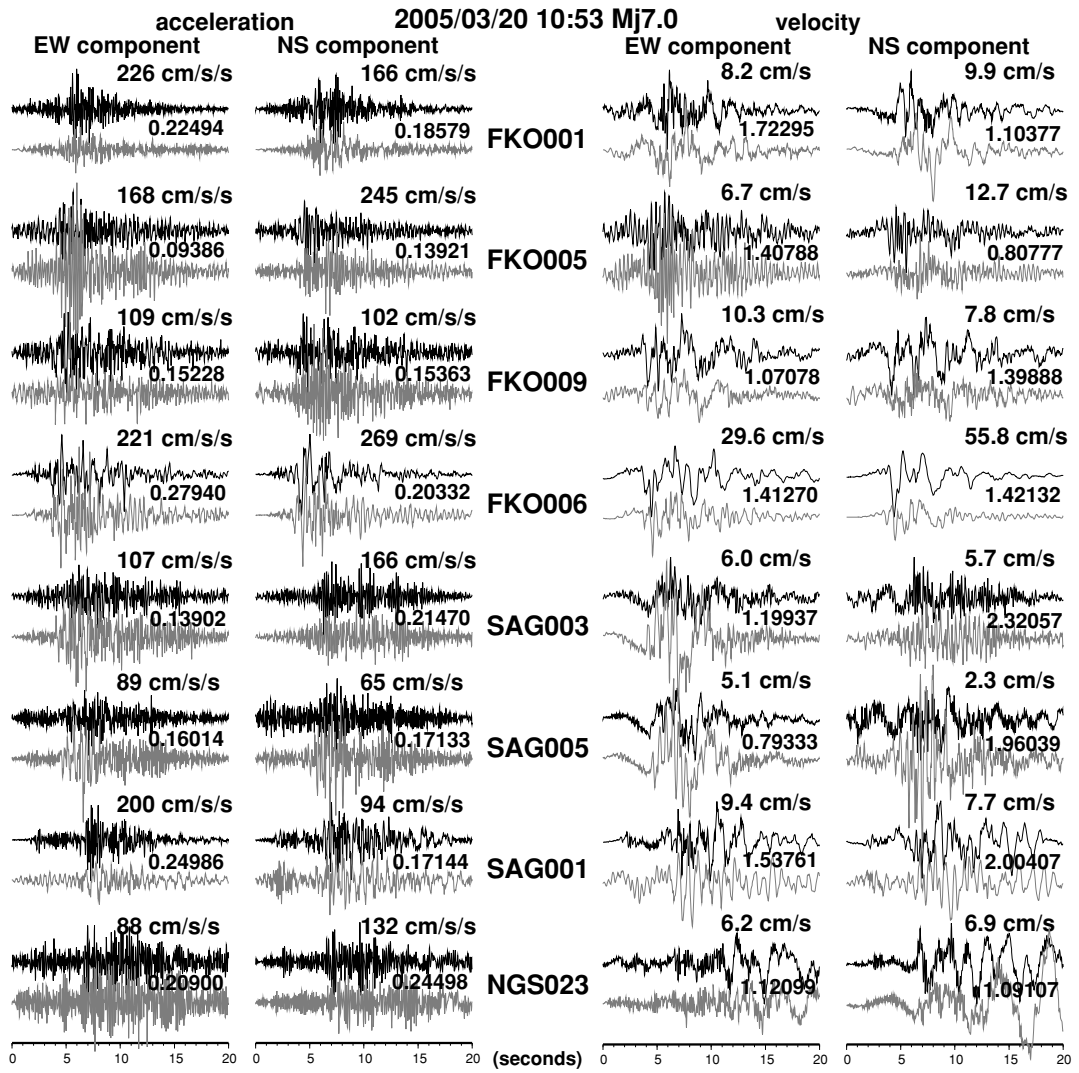

Fig. 4. Comparison between the observed and synthetic waveforms of the mainshock for $0.2-10 \mathrm{~Hz}$. The upper black lines are observation and the lower gray ones are simulation for each station. Each trace is normalized by the maximum amplitude of the observed waveforms described in the upper right. Residual values of the acceleration envelopes $(0.2-10 \mathrm{~Hz})$ and the velocity waveforms $(0.2-1 \mathrm{~Hz})$ are indicated between the observed and the synthetic waveforms.

Table 4. Estimated parameters of the SMGA of the largest aftershock (upper) and the variation of each parameter for 10 trials when rupture velocity is $2.45 \mathrm{~km} / \mathrm{s}$ (lower). The location of the SMGA is found in Fig. 2.

\begin{tabular}{cccc}
\hline Length & Width & Rise time & Rupture velocity \\
\hline $3.5 \mathrm{~km}$ & $4.5 \mathrm{~km}$ & $0.16 \mathrm{~s}$ & $2.45 \mathrm{~km} / \mathrm{s}$ \\
$2.9-3.5 \mathrm{~km}$ & $3.7-4.7 \mathrm{~km}$ & $0.16-0.20 \mathrm{~s}$ & \\
\hline
\end{tabular}

Using this formula, the stress drop of the SMGA is calculated to be $10.7 \mathrm{MPa}$ with the seismic moment $7.2 \times 10^{18}$ $\mathrm{Nm}$, the length $4.1 \mathrm{~km}$, and the width $10.2 \mathrm{~km}$. Seismic moment of the SMGA is calculated from multiplying that of the EGF event by the flat level of the spectral ratio, $C N^{3}$.

\section{Estimation of SMGA for the Largest After- shock}

\subsection{Data and analysis procedure}

Source parameters of the largest aftershock and the EGF event are listed in Table 3. As shown in Fig. 2, the hypocenters of the two events are near each other and the focal mechanisms are similar. The procedure for estimating the model parameters is the same as the analysis of the mainshock, except that the rupture of the SMGA is assumed to start from the hypocenter. $N$ and $C$ was determined to be 4 and 1.5, respectively. We compared the records of the seven stations shown in Fig. 1 for $10 \mathrm{~s}$ starting $2 \mathrm{~s}$ before the $S$ wave arrival. We used the downhole data for the SAGH01 (KiK-net). Analyzed frequency band for the largest aftershock was $0.3-10 \mathrm{~Hz}$.

\subsection{Result}

The estimated parameters of the SMGA are listed in Table 4. The SMGA extends to the southeast of the hypocenter from which rupture started and propagated towards the southeast. Aftershocks for one day after this earthquake seem to occur at the edge of the SMGA (Fig. 2). The stress drop of the SMGA is estimated to be 1.4 MPa using Eq. (2). As shown in Fig. 5, the main characteristics of broadband waveforms are explained well both in the accelerations and velocities.

\section{Discussion}

A comparison of the SMGA of the mainshock and the slip distribution deduced by Asano and Iwata (2006) is shown in Fig. 6. We use the same hypocenter location and fault geometry as those used in their study. The estimated SMGA more or less corresponds to the large slip area, although we assumed one SMGA for the mainshock analysis. The SMGA of the largest aftershock also almost corresponds to the large slip area of the largest aftershock inferred by Asano and Iwata (2006). Rupture of the mainshock SMGA started at the deepest and farthest subfault of the SMGA with respect to the hypocenter. This shows that the strong forward directivity effect toward the 


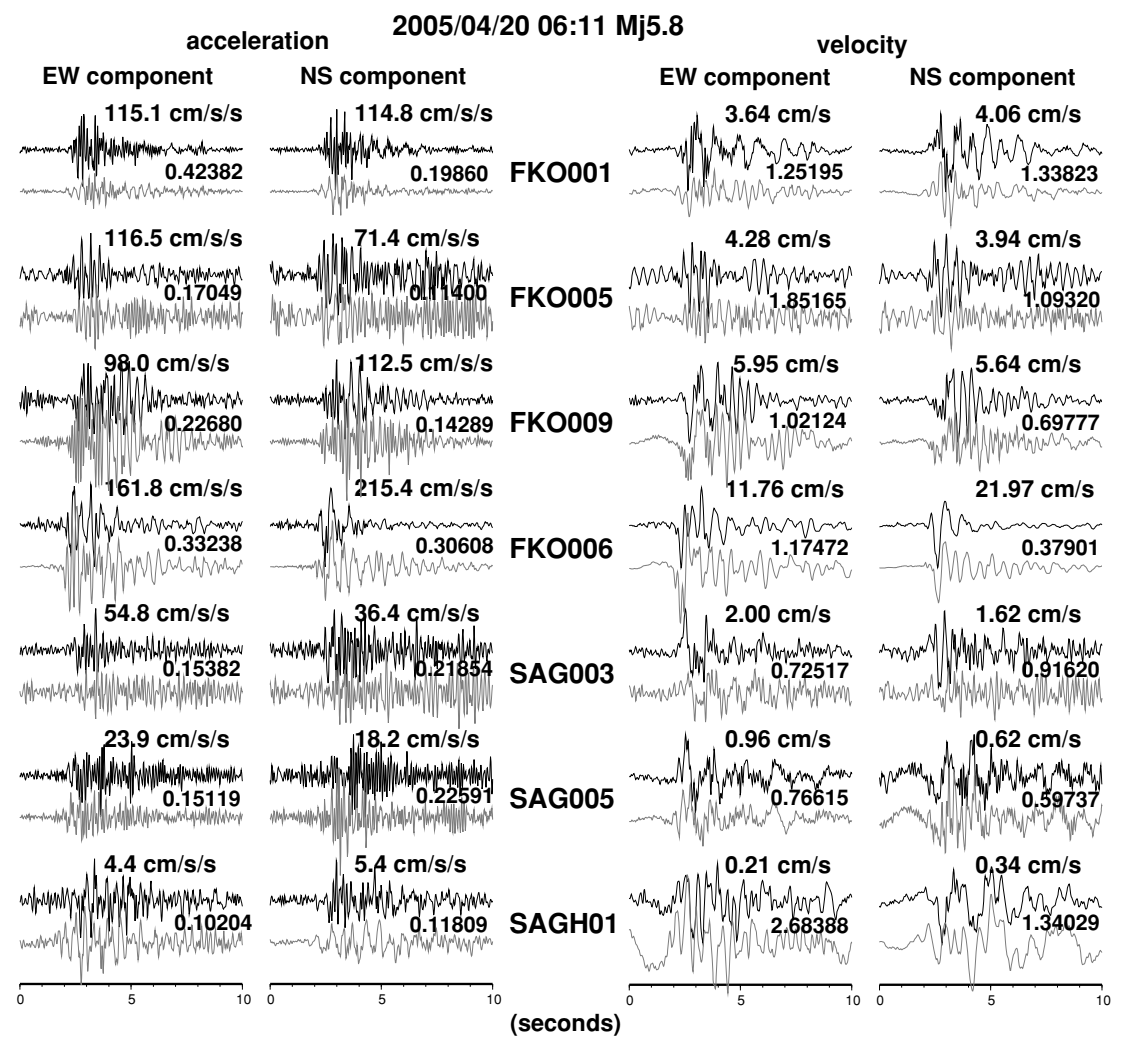

Fig. 5. Comparison between the observed and the synthetic waveforms of the largest aftershock for $0.3-10 \mathrm{~Hz}$. The black lines are observation and the gray ones are simulation for each station. Each trace is normalized by the maximum amplitude of the observed waveforms described in the upper right. Residual values of the acceleration envelopes $(0.3-10 \mathrm{~Hz})$ and the velocity waveforms $(0.3-1 \mathrm{~Hz})$ are indicated between the observed and the synthetic waveforms.

strike (southeast) direction was not detected although this could be expected from the geometrical arrangement of the hypocenter and the SMGA. In fact, it seems that the rupture of the large slip area did not significantly propagate toward the strike direction but rather propagated upwards, as can be also seen in the snapshot of rupture evolution estimated by Asano and Iwata (2006). Our results indicate that the rupture of the SMGA mainly propagated upward.

Miyake et al. (2003) estimated the stress drop in the SMGA of three crustal earthquakes whose moment magnitudes are 5.8, 5.9 and 6.0 to be about $10 \mathrm{MPa}$. The stress drop of the mainshock SMGA estimated in this study, 10.7 $\mathrm{MPa}$, is almost the same value as their results although a simple comparison might not be appropriate since they calculated the stress drop using the formula for the asperity model. For the largest aftershock, the SMGA stress drop, 1.4 MPa, is significantly smaller than that of the mainshock. Large stress drop ratio, $C=13.3$, obtained in the mainshock analysis indicates the smaller stress drop of the EGF in comparison with the mainshock. The EGF event for the largest aftershock also has as small stress drop as the largest aftershock SMGA because $C$ is 1.5 .

It has been shown that the SMGA sizes of the crustal earthquakes are self-similar and can be predicted from the empirical relation between the asperity size and the seismic moment obtained by Somerville et al. (1999) (e.g. Ikeda et al., 2002; Miyake et al., 2003; Kamae et al., 2005). We plot the SMGA size to the seismic moment for the mainshock and the largest aftershock with the empirical relation

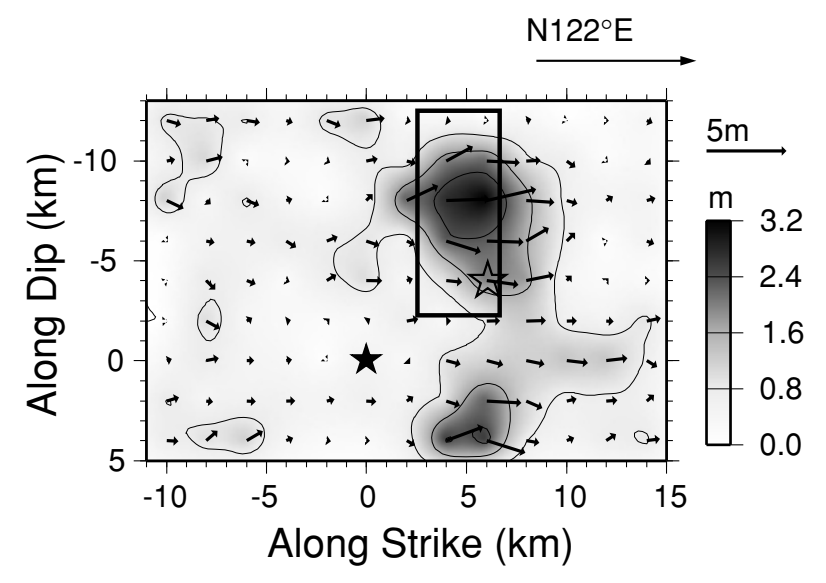

Fig. 6. Comparison of the SMGA and slip distribution deduced by Asano and Iwata (2006). Rectangle is the estimated SMGA with open star indicating the rupture starting subfault. Black star is the hypocenter of the mainshock.

by Somerville et al. (1999) in Fig. 7. The size of the mainshock SMGA is a little smaller than that predicted by the empirical formula but seems to be inside of the scattering of other earthquakes' sizes used for derivation of the formula. Contrary, the SMGA size of the largest aftershock was rather larger than the predicted value. Size of the EGF events corresponds to the subfault size of the SMGA. It is, then, observed that the sizes of the aftershocks used as EGF events for the mainshock and the largest aftershock are also 


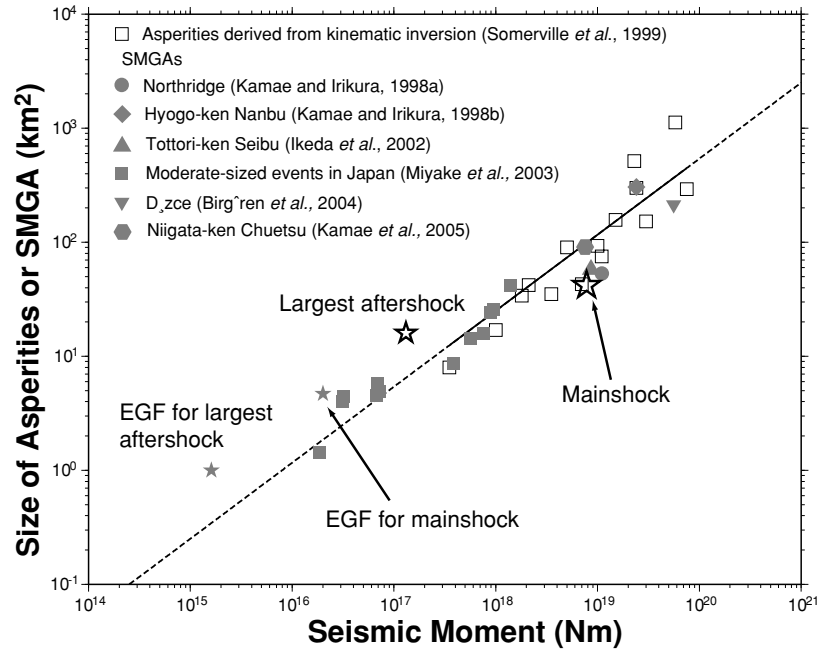

Fig. 7. Relationship between the SMGA size and the seismic moment for the mainshock and the largest aftershock (open stars). The size of the EGFs used in this study is also plotted by gray stars. Solid line shows the empirical relationship for total asperity size, based on a compilation of crustal earthquakes by Somerville et al. (1999) and the dashed lines are its extrapolation. Open squares are asperity sizes used to derive this empirical formula and gray symbols are the SMGA sizes estimated in the other studies.

larger as shown in Fig. 7. As stated previously, the stress drop of the largest aftershock SMGA and these EGF aftershocks is smaller than that of the mainshock SMGA. These difference may reflect difference of the rupture process between the mainshock and the aftershocks.

\section{Conclusion}

We estimated the SMGA of the mainshock and the largest aftershock of the 2005 west off Fukuoka prefecture earthquake. Model parameters are found by fitting the waveforms synthesized by EGF method proposed by Irikura (1986) into the observed ones over a broadband frequency range using the GA. The estimated SMGA of the mainshock is located on the large slip area deduced by Asano and Iwata (2006). The SMGA rupture mainly propagated upwards with the velocity of $3.15 \mathrm{~km} / \mathrm{s}$. The stress drop of the mainshock SMGA is $10.7 \mathrm{MPa}$, which is larger than that of the largest aftershock SMGA and the EGF aftershocks. Although the size of the SMGA of the mainshock is a little smaller whereas the sizes of the largest aftershock's SMGA and EGF aftershocks are a little larger than those predicted by the empirical relationship by Somerville et al. (1999), they approximately follow the empirical relation.

Acknowledgments. We used the strong motion records of KNET, KiK-net, and F-net maintained by National Research Institute for Earth Science and Disaster Prevention (NIED). We used the hypocentral information determined by Kyushu University and JMA, and the focal mechanisms determined by F-net and Hi-net maintained by NIED. We thank the staffs in these institutes for their continuous efforts to maintain the systems so as to obtain high quality data. Most figures were drawn by GMT 4.0 (Generic Mapping Tools, Wessel and Smith, 1995). Comments from a reviewer (Dr. Martin Mai) improved the manuscript. This study is partially supported by Grant-in-Aid for Special Purposes (17800001, PI. Prof. Kawase, Kyushu University) and the Special Project for Earthquake Disaster Mitigation in Urban Areas of the Ministry of Education, Culture, Sports, Science, and Technology, Japan.

\section{References}

Asano, K. and T. Iwata, Source process and near-source ground motions of the 2005 West Off Fukuoka Prefecture earthquake, Earth Planets Space, 58, this issue, 93-98, 2006.

Birgören, G., H. Sekiguchi, and K. Irikura, Rupture model of the 1999 Düzce, Turkey, earthquake deduced from high and low frequency strong motion data, Geophys. Res. Lett., 31, L05610, doi:10.1029/ 2003GL019194, 2004.

Horikawa, H., Rupture process of the 2005 West Off Fukuoka Prefecture, Japan, earthquake, Earth Planets Space, 58, this issue, 87-92, 2006.

Ikeda, T., K. Kamae, M. Miwa, and K. Irikura, Source characterization and strong ground motion simulation of the 2000 Tottori-ken Seibu earthquake using the empirical Green's function method, J. Struct. Constr. Eng., AIJ, 561, 37-45, 2002 (in Japanese with English abstract).

Irikura, K., Prediction of strong acceleration motions using empirical Green's function, Proc. 7th Japan Earthq. Eng. Symp., 151-156, 1986.

Kamae, K. and K. Irikura, A source model of the 1994 Northridge earthquake $\left(\mathrm{M}_{\mathrm{W}}=6.7\right)$, Proc. 10th Japan Earthq. Eng. Symp., 643-648, 1998a (in Japanese with English abstract).

Kamae, K. and K. Irikura, Source model of the 1995 Hyogo-ken Nanbu earthquake and simulation of near-source ground motion, Bull. Seism. Soc. Am., 88, 400-412, 1998b.

Kamae, K., T. Ikeda, and S. Miwa, Source model composed of asperities for the 2004 Mid Niigata Prefecture, Japan, earthquake $\left(\mathrm{M}_{\text {IMA }}\right)$ by the forward modeling using the empirical Green's function method, Earth Planets Space, 57, 533-538, 2005.

Kanamori, H. and D. L. Anderson, Theoretical basis of some empirical relations in seismology, Bull. Seism. Soc. Am., 65, 1073-1095, 1975.

Knopoff, L., Energy release in earthquakes, Geophys. J., 1, 44-52, 1958.

Kobayashi, R., S. Miyazaki, and K. Kohketsu, Source processes of the 2005 West Off Fukuoka Prefecture earthquake and its largest aftershock inferred from strong motion and 1-Hz GPS data, Earth Planets Space, 58, this issue, 57-62, 2006.

Miyake, H., T. Iwata, and K. Irikura, Source characterization for broadband ground-motion simulation: kinematic heterogeneous source model and strong motion generation area, Bull. Seism. Soc. Am., 93, 2531-2545, 2003.

Sekiguchi, H., S. Aoi, R. Honda, S. Morikawa, T. Kunugi, and H. Fujiwara, Rupture process of the 2005 West Off Fukuoka Prefecture earthquake obtained from strong motion data of K-NET and KiK-net, Earth Planets Space, 58, this issue, 37-43, 2006.

Somerville, P., K. Irikura, R. Graves, S. Sawada, D. Wald, N. Abrahamson, Y. Iwasaki, T. Kagawa, N. Smith, and A. Kowada, Characterizing crustal earthquake slip models for the prediction of strong motion, Seism. Res. Lett., 70, 59-80, 1999.

Wessel, P. and W. H. F. Smith, Free software helps map and display data, EOS, 72, 441, 445-446, 1995.

W. Suzuki (e-mail: suzuki@egmdpri01.dpri.kyoto-u.ac.jp) and T. Iwata 